\title{
Rural Tourism Destination Strategy through SWOT Analysis in Kg. Kolosunan, Penampang, Sabah
}

Fiffy Hanisdah Saikim ${ }^{1}$, Robert Francis Peters ${ }^{1}$, Nattana Simon ${ }^{1}$, Tracy Anak Angki ${ }^{1}$ \& Awangku Hassanal Bahar Pengiran Bagul ${ }^{2}$

${ }^{1}$ Institute for Tropical Biology and Conservation, Universiti Malaysia Sabah, Sabah

${ }^{2}$ Faculty of Business, Economics and Accountancy, Universiti Malaysia Sabah, Sabah Email:fiffy@ums.edu.my

DOI: https://doi.org/10.37134/jcit.vol10.4.2020

Cite this paper (APA): Saikim, F. H., Peters, R. F., Simon, N., Angki, T., \& Pengiran Bagul, A. H. B. (2020). Rural Tourism Destination Strategy through SWOT Analysis in Kg. Kolosunan, Penampang, Sabah. Journal of Contemporary Issues and Thought, 10, 36-45. https://doi.org/10.37134/jcit.vol10.4.2020

\begin{abstract}
Kg. Kolosunan is located upstream from Babagon dam in Sabah and currently gazetted as Babagon water catchment area. Since then, human activities on land and river within the vicinity of the dam has since been restricted by local authorities. This has affected local communities'livelihood that has traditionally depended on farming and river fishing to source for food. Chosen as a pilot project for Payment for Ecosystem Services (PES) since 2015, this project aims to educate and gain support from the local communities to conserve the area. This paper explores the potential(s) of ecotourism in Kg. Kolosunan as an alternative livelihood for the local community which were affected by resource use restriction due to the gazettement of the water catchment area. Data collections were done through survey, in-depth interviews analyzed using SWOT analysis and finally from previous reports. Results showed that the existing ecotourism in Kg. Kolosunan has the potential to be developed as a sustainable ecotourism site. SWOT analysis also identified the requirement management strategies to improve tourism development in Kg. Kolosunan.
\end{abstract}

Keywords: Kg. Kolosunan; Ecotourism; Alternative Livelihood; SWOT Analysis

\section{Introduction}

The Babagon dam is a concrete rockfill dam with embankment height of 70 metres and a length of 325 metres with a total of the catchment area is 30 square kilometers, is located on the Babagon-Tampasak River about two kilometers upstream from the confluence with Moyog River, one of the major rivers in the Penampang district (Yong, 2000). The Sabah State government stressed that Babagon dam was for state development and managed by JETAMA Sdn. Bhd., the concessionaire of Water Department (Yong, 2000; SDBEC, 2015). Thus, in the name of "public interest", it invoked the Land Aquisition Ordinance (Sabah Cap. 69) to acquire 169,860 hectares $(419,732$ acres) of land compulsorily. Babagon dam plays an important role primarily to supply clean water to residents around Kota Kinabalu. According to Water Department, the Babagon Dam covers a little less than a half (48.4\%) of the whole water supply in Kota Kinabalu city (SDBEC, 2015).

Currently, Natural Resources Organization (NRO) as the secretary for Water Resources Council is proposing declaration of catchment of Babagon dam as Water Conservation Area 
and Water Protection Area under Water Resources Enacment in gazzette (SDBEC, 2015). According to the coordinates of the villages derived from GIS of CRBR develop under BBEC II the Babagon Dam includes four (4) villages, namely Kampung Tampasak, Kampung Kolosunan, Kampung Kintok and Kampung Babagon Toki were located in the catchment area. The residents living around Babagon Dam such as local community in $\mathrm{Kg}$. Kolosunan, plays an important role to maintain water quality of the fresh water ecosystem along their nearby river to Babagon dam.

$\mathrm{Kg}$. Kolosunan is located in the northeast upper stream of the Babagon dam. The local community still applied traditional farming, rubber tree plantation and they are still depending on forest source as their main socioeconomic activity. However, their agricultural activity is very limited because the uses of chemicals such as pesticides and fertilizers can affect the water quality of the river. Therefore, $\mathrm{Kg}$. Kolosunan has been selected as a pilot project for Payment for Ecosystem Services (PES) or economic incentives for biodiversity conservation by creating a "Tagal system" (5 km along the river, named Sg. Tungan) since 2014 . This "Tagal System" is a traditional practice of the Dusun community in Sabah to ensure the cleanliness of the river and maintain its sustainable stock of fish (SDBEC, 2015). In many villagers and rivers where the Tagal system applied, local communities develop alternative sustainable livelihood by promoting ecotourism based on the fish resources increased by the system, such as sports, fishing, homestay, swimming with the fish, fish massage, fish feeding venture, and related ecotourism products. IUCN (World Conservation Union, 1997) defined ecotourism as a tour (hiking, jungle trekking \& etc.) to natural area to enjoy and appreciate both nature and indigenous community culture, promoting conservation, minimum tourist impact and improving local community livelihoods through their socio-economic development.

Thus, a preliminary study was conducted in $\mathrm{Kg}$. Kolosunan by field survey and an informant interview session with the local community and their associations of the ecotourism entrepreneurship. The purpose of this study was to investigate the potential(s) of ecotourism products in $\mathrm{Kg}$. Kolosunan as an alternative livelihood. Thus, this analysis focuses on the strengths and weaknesses (internal factors - local analysis) as well as opportunities and threats (external factors - global analysis) in $\mathrm{Kg}$. Kolosunan, regarding sustainable tourism and the corresponding strategy. In this study, SWOT analysis was conducted to examine sustainable tourism development in Kg. Kolosunan. According to Reihanian et al., (2012), SWOT refers to as follows: (S) stands for strengths, while (W) stands for weaknesses of the internal environmental factors of the ecotourism site. On the other hand, external factors were classified as opportunities $(\mathrm{O})$ or threats $(\mathrm{T})$. All information was tabulated in the internal factor estimate matrix (IFEM) and the latter was tabulated in the external factor estimate matrix (EFEM).

\section{Methodology}

\section{Study Site}

$\mathrm{Kg}$. Kolosunan is located at upstream of Babagon dam with approximate 45 minutes' drive with four wheels from Inanam Town, Kota Kinabalu, Sabah. According to data gathered from informant interviews, there were about 18 household members reside in $\mathrm{Kg}$. Kolosunan. Majority of the local community are Dusun and dominated by SDA religion. The local community still applies traditional farming such as rubber tree and paddy field plantation. 
Kg. Kolosunan is located in a pristine forest where wild forest sources are still available for community daily usages i.e. bamboo, rattan, tuhau and many others.

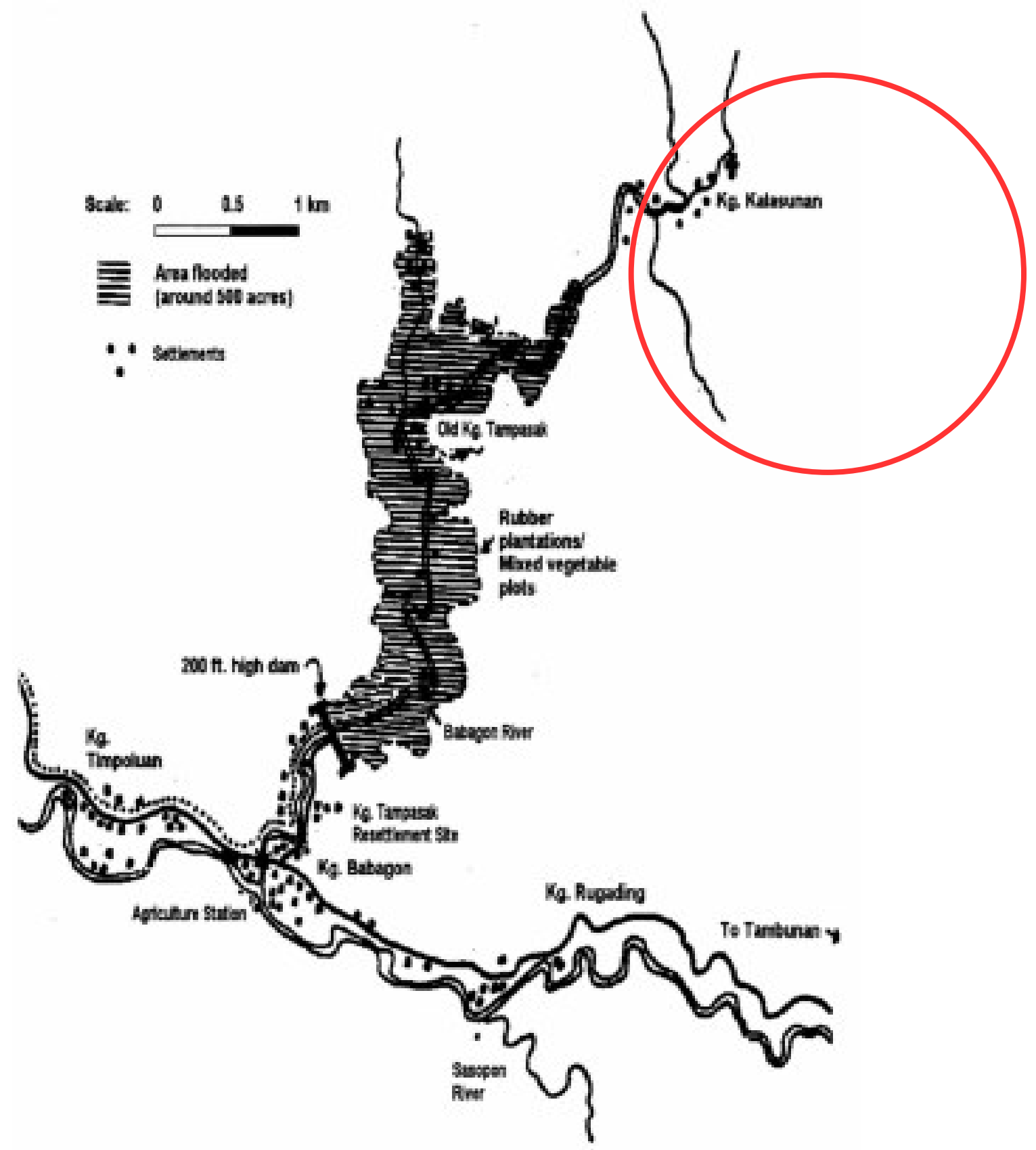

Figure 1: Location of Kg. Kolosunan

Source: Resettlement, Development \& Gender: The Case of Kampung Tampasak (Yong, 2000)

Reconnaissance Survey and Engagement with Village Committee

The first visit to $\mathrm{Kg}$. Kolosunan was conducted on 10 - 12 July 2018 where the Study Team had the opportunity to meet with Mr. Jeffrey, the Chairman of the $\mathrm{Kg}$. Kolosunan Ecotourism Association, committe members, and local villagers. The discussion enabled the Team to gain a brief glimpse into the village settings and to understand some of the issues faced by the community. 


\section{Data Resources E Analysis}

The community-based conservation study at $\mathrm{Kg}$. Kolosunan utilized primary data to develop a profile of the community. Primary data used in the report was generated through the key informants' interviews, group discussions and observations. Surveys were administered on local community regarding conservation and tourism aspects. A face-to-face survey method was employed since it is more likely to elicit higher response rates than mail surveys (Lee \& Han, 2002).

\section{SWOT Analysis}

SWOT analysis, an acronym for Strength, Weaknesses, Opportunities and Threats are used in many field especially in the business planning department (Helms et. al, 2010). It evaluates four (4) different elements of any project that involves specifying the objective of the study and able to identify both internal and external factors to achieve the objective. Internal factors will identify both strengths and weaknesses of the plan, while external factors will provide an insight on opportunities and threats presented by the environment external to the local community. Collected data was analysed using SWOT analysis and tabulated in IFEM and EFEM table. Knowledge and insight needed could be identified for managers to make strategic decisions and guide the development of their organization (Grant, 2008). Meanwhile, secondary data was collected through published reports.

\section{Results}

Based on the survey, SWOT analysis was adopted specifically for the locality to assess the ecotourism product through analyzing results and determining priorities.

\section{Internal factor estimate matrix (IFEM)}

Result identification of strengths and weaknesses of these factors can be used as internal strategic factors, given a weighting and rating for each factor. Total score values were obtained as shown in Table 3.1 IFEM matrix.

There were 17 factors identified as strengths for this project pertaining to geographical features, potential tourist attraction, basic tourism infrastructure, tourism activities, tourisms market, socio-economy background and finally skills and training. Weights of each factor were between 0.02 to 0.05 , and the effectiveness score ranges from 2 to 4 . The highest weights were given to geographical features, potential tourist attraction and socio-economy background. The highest final score was the potential tourism attraction as well as socio-economy background of community. When considering weaknesses, there were 13 factors detected. Basic tourism infrastructures such lack of accommodation and bad road access as well as the lack of clear tourism plan had the highest weight of 0.05 . The lowest weight was 0.02 , while effective score ranges between 2 and 4 . Totally, the final score for was 3.43 which is the value of internal factors implies that strengths were greater than weaknesses. 


\section{External factor estimate matrix (EFEM)}

There were 13 factors pertaining to opportunities while six (6) pertaining to threats. Tourism activities through the development of comprehensive management plan and marketing strategy had the highest weight in opportunity i.e. 0.09 while the lowest weight noted was 0.04. Threat to endemic species through habitat disturbance added by the unknown tourism carrying capacity had the highest weight of 0.08 . Rivalry from other tourism market as well as the usage of chemical fertilizers and insecticides (ecotourism demand) were given the least weight of 0.03 . The effectiveness score for both opportunities and threat were between two (2) and four (4). Ultimately, the value of external factors equalled to 3.19. This implies that opportunities precede threats.

Results are shown in Table 2, EFEM Matrix.

Table 1: Internal factor estimate matrix (IFEM)

\begin{tabular}{|c|c|c|c|c|}
\hline & INTERNAL FACTORS & WEIGHT & $\begin{array}{l}\text { EFFECTIVENESS } \\
\text { SCORE } \\
\end{array}$ & $\begin{array}{l}\text { FINAL } \\
\text { SCORE }\end{array}$ \\
\hline & \multicolumn{4}{|l|}{ Strengths (S) } \\
\hline & Geographical feature & & & \\
\hline \multirow[t]{2}{*}{1} & $\begin{array}{l}\text { Lost in the environment feeling, but location is actually very close to town; i.e. } 40 \\
\text { minutes to Inanam town \& } 1 \text { hour to KK city centre. The natural ecosystem (attraction) } \\
\text { is very well preserved, which is rare in areas close to city centres. Tourist do not need } \\
\text { to travel far to experience ecotourism. }\end{array}$ & 0.05 & 3 & 0.15 \\
\hline & Potential attraction & & & \\
\hline 2 & $\begin{array}{l}\text { Available wild flora and fauna (large fern, tuhau, butterflies etc.) including protected } \\
\text { species (Hornbill \& Rafflesia). }\end{array}$ & 0.05 & 4 & 0.2 \\
\hline \multirow[t]{2}{*}{3} & $\begin{array}{l}\text { Unique landscape featuring many types of waterfall that differs from one another, that } \\
\text { requires different scales of difficulties to reach. }\end{array}$ & 0.04 & 3 & 0.12 \\
\hline & Basic tourism infrastructure & & & \\
\hline 4 & $\begin{array}{l}\text { Beautiful camping sites are ready for tourist usage; on a flat land, close to the river. } \\
\text { Restrooms available with proper sewage system that reduces impact on the } \\
\text { environment. Power supply is also available for tourist usage in the tourist centre. } \\
\text { Traditional dining experience (halal) could be requested and prepared by local } \\
\text { communities. }\end{array}$ & 0.03 & 3 & 0.09 \\
\hline \multirow[t]{2}{*}{5} & $\begin{array}{l}\text { Clean, piped water available at tourist centre as well as houses within the kampung. } \\
\text { Gravity water are also easily available along hiking trails, and around the kampung } \\
\text { including local farms. }\end{array}$ & 0.02 & 2 & 0.04 \\
\hline & Tourism activities & & & \\
\hline 6 & $\begin{array}{l}\text { Tourism activities are centred in one place, known to the locals as their tourism centre. } \\
\text { This centre was built by locals themselves on a plot of land, by the river. There is a 2- } \\
\text { storey building used as an information centre, kitchen, one basic room and restroom } \\
\text { close to each other. }\end{array}$ & 0.03 & 3 & 0.09 \\
\hline 7 & $\begin{array}{l}\text { There are three (3) main hiking trails determined by locals themselves. All trails have } \\
\text { their own specialty \& difficulty level. Local guides will provide educational \& interactive } \\
\text { trail regarding the natural environment and their traditional uses. }\end{array}$ & 0.03 & 3 & 0.09 \\
\hline 8 & $\begin{array}{l}\text { River conservation is in place for } 3 \text { years \& with locals own initiative to implement the } \\
\text { Tagal system along their river. The zoning system that they currently have allows } \\
\text { ecotourism activities to be done including fish spa, fish feeding, fishing (catch \& } \\
\text { release) and swimming; however rules to be adhered by tourists. }\end{array}$ & 0.04 & 4 & 0.16 \\
\hline \multirow[t]{2}{*}{9} & $\begin{array}{l}\text { Various tourism activities planned including traditional and culture experience that } \\
\text { enables tourist to mingle with local community; including local fruit \& vegetable } \\
\text { farming, traditional food hunting and many others. }\end{array}$ & 0.02 & 4 & 0.08 \\
\hline & Tourism market & & & \\
\hline 10 & $\begin{array}{l}\text { Ecotourism market exist in Sabah especially Kota Kinabalu as the main entrance to } \\
\text { this state (ecotourism actively being market) would easily attract many tourists. } \\
\text { Domestic tourist and local hikers' community growing in Sabah (adventure). }\end{array}$ & 0.04 & 4 & 0.16 \\
\hline
\end{tabular}


Skills \& training

11 Local communities are actively involved in the tourism activities \& are trained regarding environmental education. They are also known as Citizen Scientist.

\section{Socio-economy background}

12 High level of community awareness \& compliance regarding biodiversity conservation. They are willing to partake in Tagal system, River Ranger, Wildlife Warden, highly engaged in creating local map and many more.

13 Community has high motivation to improve their economic situation through ecotourism; as well as the drive to implement their plans for the benefit of the environment and the peoples' socio-economic condition.

14 Restriction imposed by Government on traditional activities on water and land that helps to conserve the pristine condition of the environment.

15 Well organized community towards building ecotourism in their locality, willingness to learn and share experiences with community's vicinity kampungs.

17 Small community in the kampung, controllable number of people that could be a good start towards achieving their ecotourism plans.

\section{Weaknesses (W)}

\section{Basic tourism infrastructure}

1 The kampung is not ready to receive sleeping guests as there are no lodging options other than camping; as the community has decided not to embark on homestay programs. Restrooms are insufficient to cater a large group of visitors and the condition needs to be upgraded including power supply, additional cubicles, wash basin etc. Dining experience are limited to prior bookings only and there are no proper dining area nor restaurant or canteen options.

2 Basic infrastructures are limited to this kampung. Road access is bad, unreachable during rainy seasons and there are no alternatives into this kampung. There is also none public transport from the closest town, Inanam. Frequent power outages occur in the village and no treated water supply to houses in the kampung. In terms of communication, there is limited telco and internet connectivity.

\section{Tourism activities}

3 There are no signages throughout the kampung including tourist attractions, and there is no viewing platform of location yet.

4 The local community tourism organization has no clear report or plan structures despite being established since 2014. It also lacks marketing strategy. No firm event calendar and no clear big offerings or landmarks.

5 Increasing tourism activities might increase solid waste pollution in the kampung and they have no disposal plans yet.

$6 \quad$ Hiking as a major attraction lack basic necessities, i.e. unsuitable selection of trails, low safety, no map and signage, undetermined prices, cleanliness etc.

7 Fishing enthusiast are one of the major tourist groups that visits to experience catch $\&$ release fishing. However, there are no guidelines in place yet.

8 Fish spa (Tagal) as one of the major attraction also lack clear \& unique offer to tourist. The usage of processed fish food could affect the water quality in the long run.

9 There is no population study \& impact assessment on the bird community including the protected Hornbill and Rafflesia. Carrying capacity is unknown.

10 Historical trails (evidences \& sites) are unverified by professionals. 
11 Local volunteers in the tourism organization lacks proper training and skills in tourism

etc.

\section{Socio-economy background}

12 There are unsettled land issues with the government, or pending approval of applications by villagers that hinders further activities.

13 Decreasing volunteer motivation happened as monetary returns from tourism activities are very limited. There are also lacks of participation or limited numbers of locals in the tourism plans as the younger generation have moved out of the kampung to further study or work.

\section{TOTAL}

Table 2: External factor estimate matrix (EFEM)

\section{\begin{tabular}{|l}
\hline Opportunities (O) \\
\hline Geographical feature
\end{tabular}}

1 There are many opportunities to enhance the geographical features / landscape of 0.05 the area in order to garner more interest; including building the kampung landmark, viewing platform; agritourism etc.

2 Initial interviews records showed that biodiversity is abundant in the area, thus an opportunity for a scientific study to be done to determine population, management recommendations including carrying capacity.

\section{Basic tourism infrastructure}

3 The designated tourism area in the village is quite large and strategically located by the river thus there are rooms for improvement for development of standard buildings for canteen, kitchen, lodging and restrooms for tourism activity purposes.

4 Ecotourism activity and PES project in the kampung could be one of the justifications to hasten the approval by the Government for proper transport and communication network.

\section{Tourism activities}

5 Develop a comprehensive management plan \& marketing strategy for tourism purposes in the kampung with guidance and endorsement from relevant authorities.

6 Detailed plan of hiking trails \& water activities to be determined as per agreement with required government and kampung laws and regulations.

7 Heritage \& historical study to determine the historical allegations and management recommendations.

8 Alternative tourism activity plans that includes hands on experiences, i.e. traditional cooking class / demonstration, traditional music \& sport activity and tools making, handicraft class, traditional massage \& spa, training centre for younger generations.

\section{Tourism market}

9 As few kampung share the same natural resources and located close to each other, an ecotourism network could be considered to minimize competition.

\section{Skills \& training}

10 Training for local community on Tourism Management that covers many aspects of tourism.

\section{Socio-economy background}

11 Appointment of Honorary Wildlife Warden to local community and extension of knowledge to vicinity kampung.

12 Ecotourism activity and PES project could be a justification to expedite settlement of any land issues from relevant authorities.

13 Employment opportunity for local community in the tourism field in the kampung, and Kota Kinabalu as a whole. This would also create an avenue to appreciate efforts by local community in guarding their environment. 
1 Threat to endemic species through habitat disturbance with the introduction of mass tourism activities. This is also caused by the unknown ecotourism carrying capacity of the area.

\section{Tourism activities}

2 Community "pleas" for guidance unheard to local authorities.

Tourism market

3 Better ecotourism offers from neighbouring sites or replication of ecotourism activities in close-by areas.

Socio-economy background

4 Possible future land issues with regards to entry and usage for ecotourism purpose.

5 Usage of chemical fertilizers and insecticides to supplement the growing demand from the ecotourism industry.

6 No regulations on forest produce harvesting (medicinal, food, and craft plants) for $\quad 0.05$ local usage and tourism purpose.
0.08

$0.07 \quad 4 \quad 0.28$

$0.03 \quad 2 \quad 0.06$

$0.04 \quad 3 \quad 0.12$

$\begin{array}{lll}0.03 & 2 & 0.06\end{array}$

$\begin{array}{lll}0.05 & 3 & 0.15\end{array}$

Sustainability is the main aim in developing an ecotourism destination to ensure the return on investment could benefit the environment as well as the community in the long run. In order to assess this, a pairing of SO, WO, ST and WT, were done to identify key strategies for this particular area. S-O strategies proposed the best opportunities from the strength of the area, while $\mathrm{W}-\mathrm{O}$ strategies are identified through overcoming weaknesses that introduces opportunities. To reduce vulnerability of external threats, weakness could be reduced through assessing strengths as key to S-T strategies. S-T strategies should be able to overcome weaknesses by introducing opportunities, while $\mathrm{W}$-T strategies present a defense mechanism for the area's weaknesses from succumbing to external threats. Strengths that are not maintained may become weakness and opportunities not taken but adopted by competitors may become threats (Helms et al., 2010). The SWOT matrix identified 25 key strategies as shown in Table 3 that enlisted the external and internal factors determining the potential of the area as an ecotourism destination.

Table 3: Sustainable tourism development strategies for $\mathrm{Kg}$. Kolosunan

\section{So Strategies}

1 The Management of ecotourism in the area through community organizing shall include Community capacity building programs that addresses weaknesses identified and it shall cover socialization, training, workshop and connection building among stakeholders. These programs would be a communication tool throughout all stages, improving understanding of the tourism industry, including financial management and business as well as gaining maximum community participation.

2 The early stage of planning should include a mapping of the surrounding areas that highlights nature product potentials and their ability to support ecotourism. This stage would also identify the carrying capacity of ecotourism in the area and economic benefits to the local community.

3 Considering its particular biological and ecological conditions of the water catchment area, it should be a core factor in attracting tourist, hence an institutional setup in a form of Management Organization, Kg Kolosunan, Inanam shall spearhead the development of their Ecotourism Management Plan in order to have a clear vision and mission of including actions plans to be taken. It will also take into account current law and regulations imposed by the government on the management of the shared nature resources.

4 In the effort to develop a conservation area within the existence of community as an ecotourism destination, optimizing Government policies regarding the area of special interest (water catchment area) can be realized by creating programs, appropriate potential ecotourism products i.e.:

a) Hiking tour by exploring the forest by doing observations of wildlife and forest landscape; with special highlights at every hiking trails offered. Every trail shall be incorporated with environment education by local citizen scientist to educate visitors regarding the conservation efforts in the area.

b) Wildlife tour, namely observation activities of wildlife including birdwatching activities and also protected species watching upon agreement by various agencies

c) Botanical tour, namely observation of medicinal plants, forest plants and traditional local usages of forest plant. 
d) River activities that includes regulated fish spa, fish feeding, fishing as well as swimming within the Tagal river.

e) Village tour activities i.e. visiting houses and community farms to observe the activities of everyday life of the local people and provide interaction chance.

f) Cultural and traditional lessons of music, dance, handicraft, farming, dining experience that incorporates sustainability education to travelers.

g) Various unique tourism packages from basic package to complete overnight experience in the area depending on the length of stay.

$5 \quad$ Planned and unique marketing strategies should be adopted to gain more interest in the village, especially on the conservation efforts that supports ecotourism with these strategies;

a) Develop a comprehensive marketing strategy that adheres to laws and regulations.

b) Creates a destination image that accentuates the uniqueness of the water catchment area, coupled with local conservations efforts that could be extended to visitors and cultural values that cultivate ongoing education with the development of ecotourism.

c) Cooperating with Government agencies, non-governmental organizations, private sectors (main tourism players), and educational institutions in promoting the uniqueness of the travel experiences.

6 Advantage should be taken of the area's location, which is very close by to Kota Kinabalu city while planning for a sustainable tourism and should include the preservation of local culture and traditions as well as ecological values it has. Relevant government agencies to guide the community organization in management and marketing aspects of the industry.

\section{ST Strategies}

1 A plan on safeguarding the ecosystem of the area should be incorporated in the overall Ecotourism Management Plan of the area to avoid tourism negative impact to the sensitive environment, in order to conserve their ecological value. This should be done in accordance in International and National laws and regulations. This would also include Environmental Impact Assessment for any projects within and around the water catchment area.

2 Increase awareness regarding conservation water catchment area including the PES plan; marketing of ecotourism must be smart and unique to garner interest amongst visitors in giving contribution while on holiday and that every penny is worth to be spent there.

3 Transparent on money spent for conservation purposes in the area to attract more environmental-aware people to contribute / visit the area.

4 Build an ecotourism network with vicinity kampung instead of replication that creates more competition. With good networking and specialization, better tourism quality could be offered to visitors and also for better-spread gains for the community.

5 Upgrade basic infrastructure especially road networks to ease tourism activities.

6 Environment education to visitors by citizen scientist from the area.

\section{WO Strategies}

1 Provide accommodation for overnight and long stays.

2 Provide dining options, including canteens for visitors.

3 Communicating and introducing the areas' attractions by well-designed educating packages.

4 Environmental education building through public media, academia, government agencies and NGO's.

5 Collaborate with government agencies and tour companies to uphold the ecotourism activities in the area, including from the early planning stage.

6 Allocating budget, including sourcing activities to establish tourism infrastructures.

\section{WT Strategies}

1 Building road networks to the area, suitable for tourism including public transportation.

2 Establish a carrying capacity of tourism activities to avoid congestion as well as to preserve the ecosystem.

3 Infrastructure development harmonized with population increase caused by tourist visits.

4 Informing ecotourists and tourists by local guides, handing out brochures, and erecting signs to prevent uneventful experience.

5 "Tagging" program with relevant government agencies pertaining to training and skills upgrading of local community involved in the ecotourism plan. Experts will educate and guide communities on specific issues identified.

6 Plan to establish a network with travel agencies to market the ecotourism products. 


\section{Conclusion}

This study examines the strengths, weaknesses, opportunities and threats of tourism development in $\mathrm{Kg}$. Kolosunan. The main issues which influences tourism industry development in Kg. Kolosunan have been identified by SWOT analysis. The current and future situation of tourism in $\mathrm{Kg}$. Kolosunan depends on means of quantified SWOT analysis. It has been identified that $\mathrm{Kg}$. Kolosunan is a potential ecotourism destination as it harbors ecotourism products. The strong points are their location, i.e. short travel distance from the city centre of Kota Kinabalu city paired with serene natural environment. The community initiative "Tagal System" and clean river stream, challenging and adventurous trail, unique waterfall structure, great diversity of environments including protected species of flora and fauna (e.g. rafflesia and hornbill), beautiful landscape with Babagon dam view and existence of valuable natural areas that may be further enhanced in terms of enjoyment areas that can be integrated with ecotourism. Ecotourism in this water catchment area also provides an opportunity for visitors to contribute and be actively involved in environment education and conservation. However, the right marketing strategy needs to be accurate that supports the implementation of the ecotourism management plan of the whole area. Issues needs to be addressed are basic infrastructure and product marketing that is inadequate, due to local government's lack of attention to create better tourism opportunity. At the same time, capacity building amongst local community that includes skills and training has been identified as a key strategy to ensure the success of the ecotourism plan. These study results could help decision makers and stakeholders to determine their respective actions plans. Consequently, this paper provides an important alternative for further research projects on implementation of sustainable tourism in $\mathrm{Kg}$. Kolosunan and its nearby area.

\section{References}

Grant, R.M. (2008). Why strategy teaching should be theory based. Journal of Management Inquiry, 17(4), 276281.

Helms, M.M., \& Nixon, J. (2010). Exploring SWOT analysis-where are we now?: A review of academic research from the last decade. Journal of Strategy and Management, 3(3), 215-251.

Kinnear, T., \& Taylor, J.M.H. (1995). Marketing research, an applied approach. New York: McGraw Hill Higher Education.

Lee, C.K., \& Han, S.Y. (2002). Estimating the use and preservation values of national parks' tourism resources using a contingent valuation method. Tourism management, 23(5), 531-540.

Reihanian, A., Mahmood, N.Z.B., Kahrom, E., \& Hin, T.W. (2012). Sustainable tourism development strategy by SWOT analysis: Boujagh National Park, Iran. Tourism Management Perspectives, 4, 223-228.

SDBEC (2015). Economic toward sustainable development for biodiversity \& ecosystem conservation in Sabah. Retrieved on 15/07/2018 at https://www.jica.go.jp/oda/project/_component/r7mcj0000001x00vatt/jica_report.pdf.

Yong, O.L. (2000). Resettlement, development and gender: the case of the Kadazandusun of Kampung Tampasak, Penampang, Sabah/Yong Ooi Lin (Doctoral dissertation, University of Malaya). 